Accounting and Management Information Systems

Vol. 18, No. 1, pp. 119-125, 2019

DOI: http://dx.doi.org/10.24818/jamis.2019.01006

\title{
Occurrence of occupational fraud in family businesses: A Pitch
}

\author{
Sneha Raut ${ }^{\mathrm{a}, 1}$ \\ ${ }^{a}$ Bond University, Australia
}

\begin{abstract}
Idea generation is easy but getting a refined and organized form for that idea is a complex process. This letter outlines the utilization of Faff (2018) pitching research framework for developing a personal original pitch. The pitching research template is intriguing as it helps young researchers like myself in determining the core components of their research topic. This "Pitching Research Letter" features my personal thoughts on pitching research and the application of the pitching template to develop my personal pitch on "Occupational Fraud in Family Businesses" using the Fraud Triangle.
\end{abstract}

Keywords: Pitching Research, Occupational Fraud, Family Businesses, Fraud Triangle

JEL Codes: C12, C51, G40, K20, K21, M41, M48

\section{Introduction}

"The greatest of all pleasures is the pleasure of learning" - Aristotle

The art of understanding how to make a research idea a successful one is at the heart of the pitching research process. This pitching research letter is used to develop a pitch in occupational fraud and is comparable to the work of Unda (2015), Atif (2016), Rekker (2016) and Wallin and Spry (2016), which is based on pitch research template by Faff (2015) and its adaptations.

I am currently enrolled as a M.Phil. student at Bond University, Australia. Occupational fraud is my area of research and my focus is on family businesses. The

1 Corresponding author: Bond Business School, Bond University, 14 University Drive, Robina, QLD. 4226; Tel: (+61) 406525869; E-mail: sraut@ bond.edu.au 
motivation for pursuing this comes from my father, who runs a family business. Growing up in a small Indian village, looking at my father run his business involving family members, I witnessed incidents that can be quoted as "Acts of Fraud". Despite knowing that the actions were questionable, he never took any action, stating "it's a family matter". I knew it was not right and, hence, from that moment I always wanted to explore this more. On completion of my Master of Business, I wanted guidance and I reached out to my supervisor. He was involved in ongoing research in forensic accounting and related fields. This, thus, gave me the right direction towards my research idea.

On commencing with my M.Phil., I completed a course on Forensic Accounting and Fraud Examination, which further strengthened my research agenda. Later, as a part of my coursework requirement, I needed to undertake one more course, which was "Process of Research in Business". This course was delivered by Faff and that is where I first learnt about "Pitching Research".

The pitching research process was delivered to us in different formats. To make us comfortable with the usage of the pitching template, we were assigned a task called "Fantasy Pitching", as a part of our learning process. This task of "Fantasy Pitching", helped us think out of the box and encouraged us to challenge our thinking process. In this task, we worked in groups and we had to come up with an imaginary research agenda. My group was keen on researching Donald Trump and hence our "Fantasy Pitching" was titled, "Donald Trump - The Power of the Toupee: theory evidence - policy implications". This task generated enthusiasm within me for the subject.

Following this was "Reverse Engineering", a technique useful for young researchers to get a grasp of the exhaustive academic literature. The template of "Reverse Engineering" is similar to the "Pitching Research" template, however what is different is the output. The "Reverse Engineering" template is productive for streamlining the literature and understanding the complex journal articles. The template has questions that helps to get a succinct summary of the complex paper, helping early researchers to have a systematic learning process. This technique is useful to deconstruct the key papers in one's research, helping one to have a strong hold over the literature. I used this template to reverse engineer key and seminal papers in my research field, which helped me handle the huge and complex literature.

Learning the various formats of "Pitching Research" and implementing them throughout the learning journey, our last task was to generate an original personal pitch using the "Pitching Research Template" by Faff. The remainder of this pitching letter will focus on the implementation of the template to create the original pitch as well as provide some personal insights on the "Pitching Research" process. 


\section{Succinct Explanation on exercising the Pitching Template}

The "Pitching Research" template is a systematic framework, Faff calls it the "4-32-1" framework in his Faff (2018) Pitching Research ${ }^{\circledR}$. Further, he breaks it into labels from (A) to (K). I will explain the "4-3-2-1" application with my completed 2-page pitch template on "Occurrence of Occupational Fraud in Family Businesses" as shown in Table 1. The essence of the pitch is occupational fraud and the key theoretical framework used extensively is Cressy's Fraud Triangle Theory, which forms the backbone of this research as well as the pitch.

Standing at the crest of the template is " 4 " asking to pen down the four key components (Label A - D) of the pitch (i.e. title, research question, key paper and the motivation). As you can see in Table 1, Label B, the basic research question is to explain the occurrence of occupational fraud using the three vertices of Cressey's Model. These research questions lay the foundation of my M.Phil. research and aim to fill the gaps found in the literature. Murphy and Free (2016) is my key paper. This paper utilises the fraud triangle theory and extends it in the field of occupational climate. It encouraged me to research the intersection of "Fraud Triangle Theory, Occupational Fraud and Family Business". Another factor to motivate me in looking at this area was the lack of research correlating occupational fraud and family business. Dorminey et al. (2012) elaborated on the evolution of fraud theories; it was fascinating to see how Cressy's Fraud Triangle Theory formed the base of each new theory and model. Hence, I knew my base was going to be recent papers based on the original theory coined by Cressy (1950) like Murphy and Free (2016).

Moving to "3" (i.e. label E-G), also popular as the "IDioTs" guide as per Faff (2018), this component of the template is based on the core aspects of the empirical research. Label E - Idea, it wants us to identify the "core" that urge this research topic with the variables involved. Label F \& G - Data and Tool, ask to explain the data collection methodology and the tools that will assist in the research analysis.

Down to "2" (i.e. label H - I), the two key questions are; "What" \& "Why"? This component of the template helps to further emphasize on the research topic by asking two things. What's New? and So What? This part showcases the novelty of the research topic and why it is important to get an answer for this research agenda.

Coming down to the one bottom line, "1", label J, here we show what is the primary contribution to the existing literature as well as the practical applications of this research. This sums up the "4-3-2-1" countdown but we have one more label left, " $\mathrm{K}$ ". This is the hidden part of the "4-3-2-1" countdown, there is " +1 " summing up the label count. What is " $\mathrm{K}$ "? it is an add on where you can jot down other considerations important for this research topic. You can mention funding, collaboration, ethics, tool, data collection and anything that will have a direct effect 
on the functioning of the research and its probable outcome. Table 1 summarises the "4-3-2-1 \& +1" with my research topic.

\section{Personal contemplation on pitching research exercise}

Faff (2018) stated that for an amateur researcher to know where exactly to start is a tough task. I took the pitching research idea from prior work done by Salehudin (2017) on reverse engineering along with Rekker (2016), Wallin and Spry (2016), Beaumont (2015) and Ratiu (2015) pitching experience to kick start my pitching journey. This helped me define my research agenda and narrow down my research topic. I was under the impression that research is all about reading continuously. After receiving the pitching template, I saw how one can have key takeaways of the main readings in one place. Trying to question myself about what is unique in my research never helped until I was introduced to the "Mickey Mouse Diagram" as seen below as Figure 1. This helped me get the core intersection of various key elements of my research and now I can say confidently what is novel in my research.

What did I gain from this pitching research process? I have learnt a technique that made my researching interesting and objective. Having the template in my hand, I know what I am looking for and where I can find the answers within the article, by the end of the read, I have succinct information of the article that can be used at any point. Along with the ease of researching, I learnt how this template can be used for brainstorming about new research ideas as well as how it can be used for collaborative team effort also. Another takeaway from the entire learning process is, I have learnt to read within the lines and that I have understood that research is a collaborative process. It might be your idea and your work but, in the end, it is based on past work done by someone or referring to papers written by some or an extension of an idea. Thus, what I learnt about research is that is inclusive and collaborative in nature.

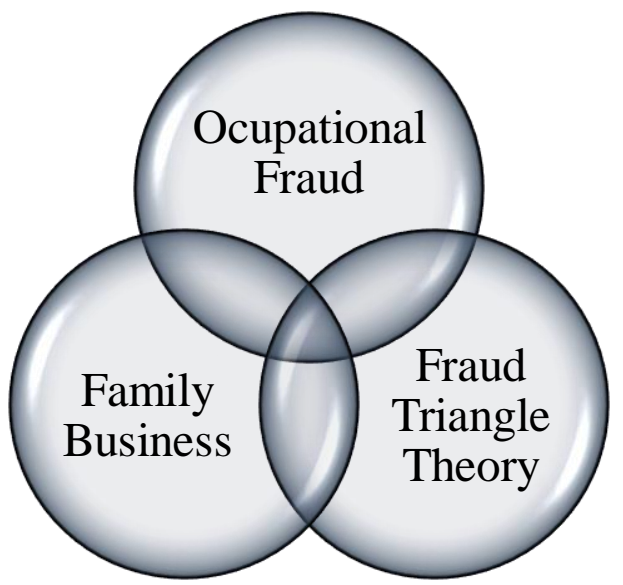

Figure 1. Mickey Mouse Diagram 


\section{Conclusion}

This pitching letter provided succinct information on the occurrence of occupational fraud in family businesses. This pitching letter was developed utilising Faff (2018) pitch template. The original pitch developed, forms the foundation of my M.Phil. It showcases how the modified form of the template was used to reverse engineer key and seminal papers and to create the original pitch. I am grateful to have come across this template to accompany me. This template had made the complex literature review as well as the refinement of research idea journey a smooth one. I will personally recommend it to any novice researcher to grasp the cumbersome journey of research.

\section{Acknowledgement}

This Pitching Research Letter is the first step of author's M.Phil. journey. The author is thankful to Robert Faff for delivering the subject Process of Research in Business at University of Queensland and giving us the knowledge of a great tool, "Pitching Template". The author is thankful to other authors who have previously written Pitching Research Letters that helped me experience the way a Pitching Research Letter should be written.

\section{References}

Atif, M. (2016) "CEO Compensation and Firm's Cash Holding: A Pitch", Accounting and Management Information Systems, vol. 15: 605-611

Faff, R. (2018) “Pitching Research®”, SSRN Electronic Journal, Available at SSRN: https://ssrn.com/abstract=2462059 or http://dx.doi.org/10.2139/ssrn.246 2059

Murphy, P.R. \& Free, C. (2016) "Broadening the fraud triangle: Instrumental climate and fraud", Behavioral Research in Accounting, 28(1): 41-56

Rekker, S. (2016) "Converting planetary boundaries into action, a new approach to meeting global greenhouse gas targets", Accounting and Management Information Systems, vol. 15: 160-167

Ratiu, R. V. (2015) "Financial reporting of European banks during the GFC: A pitch", Accounting and Finance, 55(2): 345-352

Salehudin, I. (2017) "Reverse engineering' the pitching research template: A Simple Tool to Help Understand the Academic Literature", Accounting and Management Information Systems, vol. 16: 203-210

Stokes, D. (2013) "Generating Innovative Research Ideas", Accounting and Management Information Systems, vol. 12: 144-154

Unda, L. (2015) "Board of Directors Characteristics and Credit Union Financial Performance: A Pitch", Accounting and Finance, vol. 55: 353-360

Wallin, A. \& Spry, A. (2016) "The role of corporate versus product brand dominance in brand portfolio overlap: A Pitch", Accounting and Management Information Systems, vol. 15: 434-439 
Table 1. Completed 2-page pitch template on "Occurrence of Occupational Fraud in Family Businesses

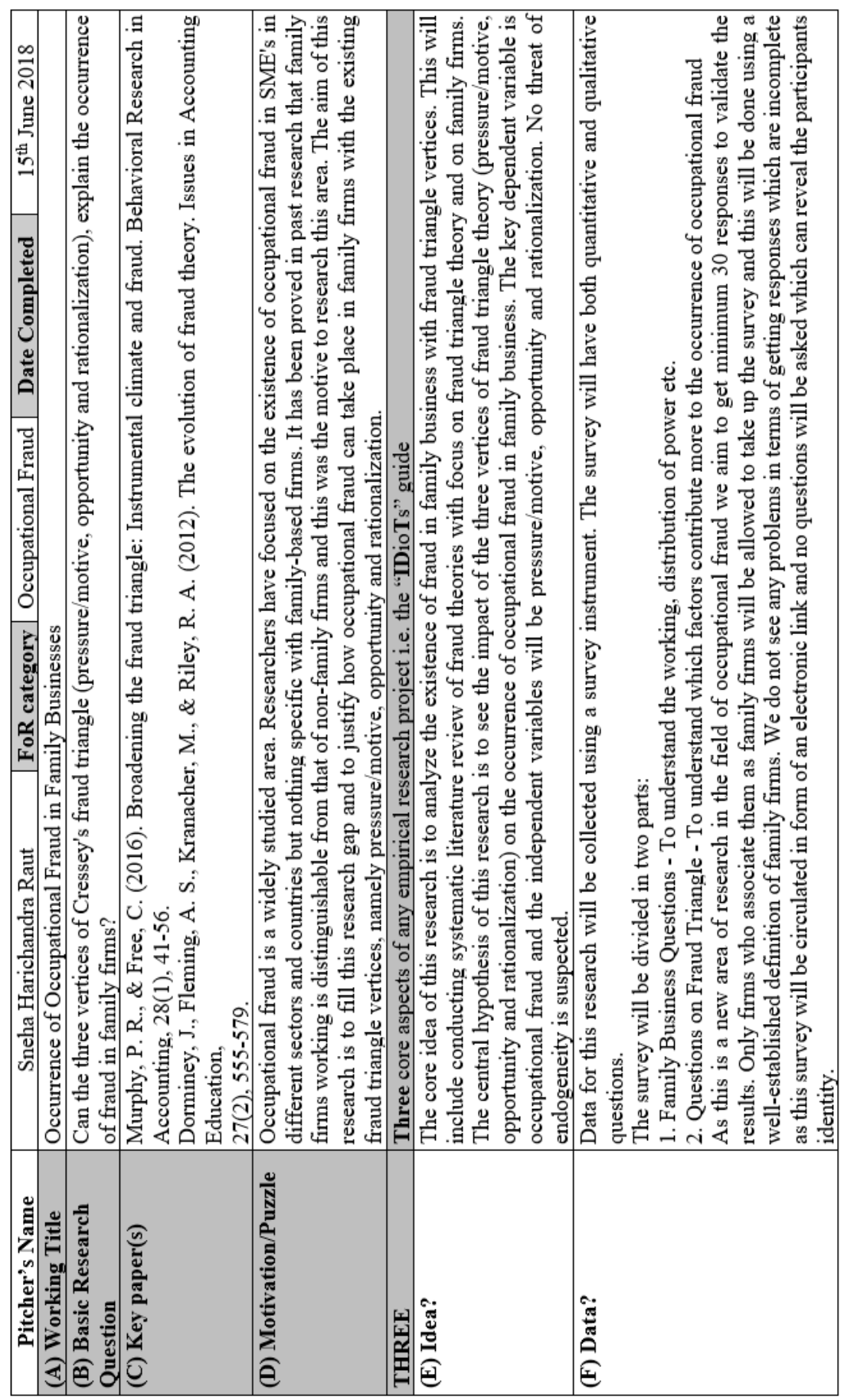




\begin{tabular}{|c|c|c|c|c|}
\hline 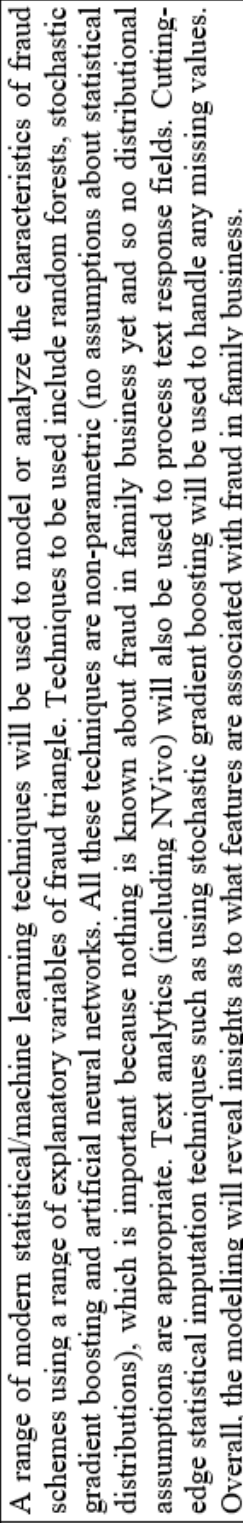 & 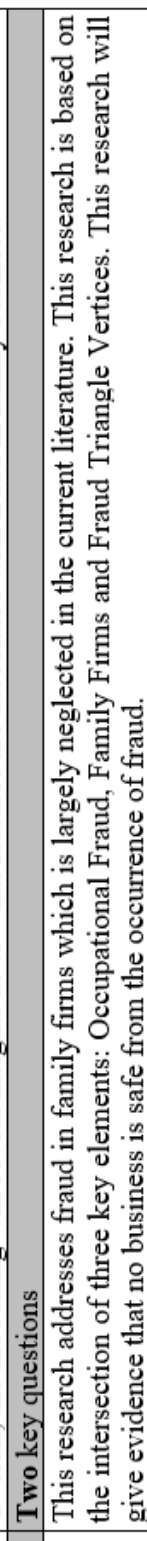 & 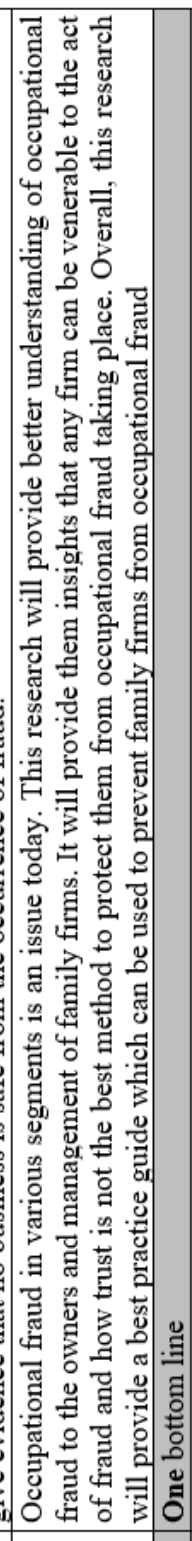 & 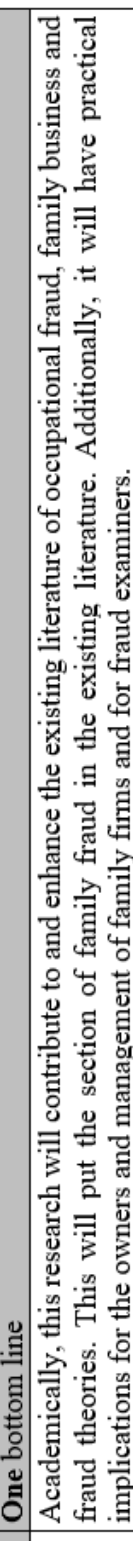 & 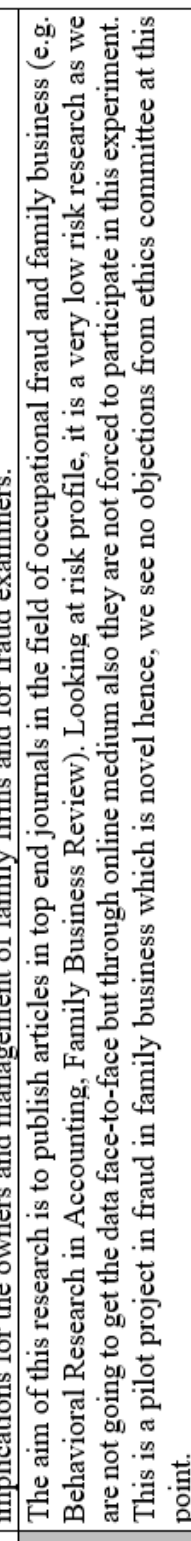 \\
\hline & $\underbrace{\infty}$ & $\stackrel{\circ}{\mathscr{n}}$ & 约 & ש \\
\hline
\end{tabular}

Vol. 18, No. 1 